\title{
Predictors of oedema among children hospitalized with severe acute malnutrition in Jimma University Hospital, Ethiopia: a cross sectional study
}

Tsinuel Girma ${ }^{1 *}$, Pernille Kæstel², Christian Mølgaard ${ }^{2}$, Kim F Michaelsen², Anne-Louise Hother ${ }^{2}$ and Henrik Friis ${ }^{2}$

\begin{abstract}
Background: Severe acute malnutrition has two main clinical manifestations, i.e., oedematous and non-oedematous. However, factors associated with oedema are not well established.

Methods: Children $0.5-14$ years of age with SAM (MUAC $<11.0 \mathrm{~cm}$ or weight-for-height $<70 \%$ of median and/or nutritional oedema) admitted to the nutrition unit were included. Information on infections before and during admission was collected together with anthropometry. Predictors of oedema was analysed separately for younger ( $<60$ months) and older children ( $\geq 60$ months).

Results: 351 children were recruited (median age: 36 months (interquartile range 24 to 60); 43.3\% females). Oedema was detected in $61.1 \%$. The prevalence of oedema increased with age, peaked at 37-59 months (75\%) and declined thereafter. Infection was more common in the younger group ( $33 \%$ vs. 8.9\%, $p<0.001)$ and in this group children with oedema had less infections $(25.2 \%$ vs. $45.1 \%, p=0.001)$. In the older group the prevalence of infections was not different between oedematous and non-oedematous children (5.5\% v. $14.3 \%, p=0.17)$. In the younger group oedema was less common in children with $T B(O R=0.20,95 \% \mathrm{Cl}: 0.06,0.70)$ or diarrhea $(\mathrm{OR}=0.40$, 95\% Cl: 0.21, 0.73).

Conclusions: The proportion of oedema in SAM peaked at three to five years of age and a considerable proportion was above 5 years. Furthermore, the prevalence of infection seemed to be lower among children with oedema. Further studies are needed to better understand the role of infection-immunity interaction.
\end{abstract}

Keywords: Severe acute malnutrition, Oedema, Infection, Risk, Predictors

\section{Background}

Millions of children living in low-income countries suffer from undernutrition; undernutrition contributes to one-third of the deaths in young children $[1,2]$. Severe acute malnutrition (SAM) affects an estimated 20 million children under 5 years of age [3]. Despite recent improvement in the protocols for treatment of SAM, case-fatality rates of $20-30 \%$ are still seen and are higher for oedematous malnutrition [4].

\footnotetext{
* Correspondence: tsinuel.girma@ju.edu.et

${ }^{1}$ Department of Pediatrics and Child Health, Jimma University Specialized Hospital, Jimma, Ethiopia

Full list of author information is available at the end of the article
}

There are two main clinical manifestations of SAM, i.e. oedematous and non-oedematous [5]. However, which factors lead to oedema and the mechanisms behind have been discussed extensively, but remains unknown. In earlier works, oedema in severe malnutrition was explained by dietary protein deficiency [6], and subsequently free-radical-mediated cellular injury was suggested as a mechanism [7]. Recently, researchers suggested a developmental origin, based on a finding in a retrospective observational study [8].

Studies of predictors of SAM are scarce but important to understand the disease process. Existing published works investigated risk factors for undernutrition in general, and mainly in children under the age of five years

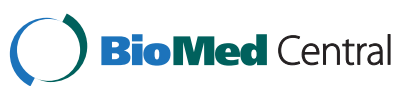


[9-13]. Large family size, poor maternal nutrition, poverty and unhygienic environment were shown to be risk factors in these studies. Regarding age and gender, however, the results were conflicting.

The aim of this study, therefore, was to identify predictors of oedema among children hospitalized with SAM in the Nutritional Rehabilitation Unit (NRU) of Jimma University Specialized Hospital (JUSH), Ethiopia.

\section{Methods}

\section{Study setting and subjects}

JUSH is located in Jimma Zone in southwest Ethiopia. It has a Paediatric Ward incorporating the NRU, and has been implementing the WHO-based National Guideline for Treatment of Severe Malnutrition [14] since 2004. The NRU receives severely wasted or oedematous patients who have no associated severe acute illness such as severe pneumonia, sepsis, or shock. Severely ill SAM patients are first stabilized in the Critical Care Unit and afterwards transferred to the NRU.

Eligibility for the study required severe wasting (MUAC $<11.0 \mathrm{~cm}$ or weight-for-height $<70 \%$ of the median of the NCHS growth reference) or nutritional oedema. Children below 6 months of age, those who had life threatening illness, such as shock, and those readmitted with SAM were excluded. Children below 6 months of age were excluded as the diagnosis and treatment of SAM is still not well standardized. Fourteen years was set as the upper age limit since older children were not accepted at the paediatric ward.

\section{Data collection}

Data on household's water source and toilet facility along with caretaker's schooling and occupation were obtained by interviewing caretakers, as were history of fever, diarrhea, cough and measles, within one month before admission to hospital. Age of the child was determined from caretakers' recall. Children were measured naked and body weight recorded to the nearest $10 \mathrm{~g}$ using a paediatric scale (Tanita BD 815 MA, Tokyo, Japan). Length was measured in recumbent position for children less than 2 years of age or not able to stand.

Length was recorded to the nearest $0.1 \mathrm{~cm}$ using a length board (SECA 416, Hamburg, Germany). When length was measured instead of height in children older than 2 years, $0.5 \mathrm{~cm}$ was subtracted from the length. For children older than 2 years, height was measured using a free-standing stadiometer and recoded to the nearest $0.1 \mathrm{~cm}$. MUAC was recorded to the nearest $0.1 \mathrm{~cm}$ using a strip (SECA 2012, Hamburg, Germany). Triceps and sub-scapular skin fold thicknesses were measured in duplicates to the nearest $0.2 \mathrm{~mm}$ using a Harpenden calliper (Baty International, West Sussex, UK). Presence of pitting oedema was checked by applying a gentle pressure with the thumb for 3-5 seconds. It was registered as " 0 " if no pitting was detected on the feet. In the presence of pitting, it was recorded as "+" if detected on feet, "++" legs and feet, and " +++ " if it included the hands and face.

Infections diagnosed during the admission were taken from the child's clinical record. The diagnosis of tuberculosis (TB) was based on clinical and radiologic data, according to the Ethiopian National Guideline [15]. Features indicative of TB were chronic symptoms or physical signs suggestive of $\mathrm{TB}$, history of exposure to adult with chronic cough or with TB and suggestive X-rays. For TB suspected children who were able to produce sputum, microscopic sputum examination for acid fast bacilli was done. Tuberculin skin test was unavailable. For febrile patients coming from a malarial area, malaria parasitaemia was examined with Wright stained thick and thin blood films. Pneumonia was diagnosed when a patient had short duration of cough ( $<2$ weeks) or respiratory difficulty, age-specific fast breathing (above normal for age category), auscultatory and/or chest $\mathrm{x}$-ray findings. Diarrhea was defined as three or more loose stools per day. The clinical case definition for measles was a generalized maculopapular rash lasting for $\geq 3$ days, fever $\left(\geq 38.3^{\circ} \mathrm{C}\right.$, if measured), and 1 of the following: cough, coryza, or conjunctivitis. Rapid antibody tests were used to diagnose HIV.

\section{Table 1 Characteristics and season of admission for} children admitted with severe acute malnutrition

\begin{tabular}{|c|c|c|c|}
\hline & $\begin{array}{l}\text { Age }<5 \text { years }^{a} \\
n=261\end{array}$ & $\begin{array}{l}\text { Age } \geq 5 \text { years }^{a} \\
n=90\end{array}$ & p-value \\
\hline Female sex & $105(40.2)$ & $47(52.2)$ & 0.05 \\
\hline Caretaker of child in hospital & & & $<0.001$ \\
\hline Mother & $151(57.8)$ & $30(33.3)$ & \\
\hline Father & $90(34.5)$ & $51(56.7)$ & \\
\hline Relative & $20(7.7)$ & $9(10.0)$ & \\
\hline Caretaker's occupation & & & 0.03 \\
\hline Farmer & $187(71.6)$ & $76(83.5)$ & \\
\hline Employed & $39(15.0)$ & $5(5.5)$ & \\
\hline Other $^{\mathrm{b}}$ & $35(13.4)$ & $9(10.0)$ & \\
\hline Caretaker's schooling & & & 0.34 \\
\hline No schooling & $170(65.0)$ & $63(70.0)$ & \\
\hline Some schooling & $91(35.0)$ & $27(30.0)$ & \\
\hline Toilet facility & $238(91.5)$ & $81(90.0)$ & 0.61 \\
\hline Safe water supplyc & $158(60.8)$ & $49(54.4)$ & 0.34 \\
\hline Admission per season $^{d}$ & & & 0.06 \\
\hline Pre-harvest & $129(49.4)$ & $55(61.1)$ & \\
\hline Post-harvest & $132(50.6)$ & $35(38.9)$ & \\
\hline
\end{tabular}

a Values are median (25th; 75th percentile) or $n(\%)$.

bUnemployed, studying or on pension.

${ }^{\mathrm{c}}$ Main source of drinking water for family is from pipe, protected spring or well.

${ }^{d}$ Pre-harvest (June -Nov) and post-harvest (Dec-May). 
Table 2 Anthropometry, presence of oedema and illnesses among 351 children admitted with severe acute malnutrition by age group

\begin{tabular}{|c|c|c|c|}
\hline & $\begin{array}{l}\text { Age }<5 \text { years }^{a} \\
n=261\end{array}$ & $\begin{array}{l}\text { Age } \geq 5 \text { years }^{a} \\
n=90\end{array}$ & $\mathrm{p}$-value \\
\hline \multicolumn{4}{|l|}{ Growth indicators } \\
\hline Weight, kg & $8.1(7.8,8.4)$ & $14.1(13.3,15.1)$ & \\
\hline Height, cm & $77.6(76.4,78.6)$ & $105.7(102.8,109.3)$ & \\
\hline BMI-for-age Z-score & $-2.4(-2.6,-2.2)$ & $-2.6(-3.1,-2.2)$ & 0.31 \\
\hline MUAC, $\mathrm{cm}$ & $11.1(11.0,11.3)$ & $12.0(11.6,12.3)$ & $<0.001$ \\
\hline Weight-for-age Z-score & $-3.7(-4.0,-3.5)$ & $-3.5(-3.8,-3.2)$ & 0.27 \\
\hline Height-for-age Z-score & $-3.4(-3.5,-3.1)$ & $-3.0(-3.3,-2.7)$ & 0.14 \\
\hline Weight-for-height Z-score ${ }^{b}$ & $-3.6(1.3)$ & & \\
\hline MUAC-for-age Z-score ${ }^{b}$ & $-4.0(-4.1,-3.8)$ & & \\
\hline \multicolumn{4}{|l|}{ Clinical } \\
\hline Bilateral pedal pitting oedema & $159(61.0)$ & $55(61.1)$ & 0.87 \\
\hline HIV status & & & 0.80 \\
\hline Negative & $172(66.3)$ & $61(67.8)$ & \\
\hline Positive & $6(2.3)$ & $3(3.3)$ & \\
\hline Unknown & $82(31.4)$ & $26(28.9)$ & \\
\hline Co-infection $(\geq 1)^{c}$ & $86(33.0)$ & $8(8.9)$ & $<0.001$ \\
\hline Pneumonia & $60(23.0)$ & $4(4.4)$ & $<0.001$ \\
\hline Diarrhea & $58(22.2)$ & $3(3.3)$ & $<0.001$ \\
\hline Tuberculosis (all forms) & $14(5.4)$ & $3(3.3)$ & 0.58 \\
\hline Malaria & $8(3.1)$ & $1(1.1)$ & 0.46 \\
\hline Reported illness $(\geq 1)^{d}$ & 237 (90.8) & $81(90.0)$ & 0.55 \\
\hline Fever & $182(70.0)$ & $69(65.6)$ & 0.48 \\
\hline Diarrhea & $169(65.0)$ & $56(62.2)$ & 0.53 \\
\hline Cough or difficult breathing & $145(55.8)$ & $42(46.7)$ & 0.18 \\
\hline Measles & $16(6.2)$ & $5(5.6)$ & 0.81 \\
\hline
\end{tabular}

${ }^{a}$ Values are mean (95\% confidence interval), mean ( \pm standard deviation) or $\mathrm{n}(\%)$

${ }^{\mathrm{b}}$ Not possible to calculate $\mathrm{z}$-score for age $>5$-years using WHO growth standard. ${ }^{\mathrm{c}}$ Major diagnoses during admission.

${ }^{\mathrm{d}}$ Reported symptoms or illness within one month before admission.

Before giving consent, caretakers were given detailed verbal and written information about the study using their language (Afan Oromo). Prior to commencing the study, ethical clearance was granted from the Research Ethical Review Committee, College of Public Health and Medical Sciences, Jimma University. Data were collected by two trained research nurses who spoke the local language. A subset of 20 malnourished children was examined by both nurses to determine percent of technical error of measurement (\% TEM). Inter-observer \%TEM was $1.1 \%$ for MUAC. For biceps, triceps, sub-scapular and suprailiac skinfolds measurements inter-observer \% TEM was between 2.6 and $4.8 \%$. Intra-observer \% TEM for MUAC was $<0.5 \%$ for both nurses, whereas it was between 1.6 and $3.7 \%$ for the four skin folds. The study was conducted from December 2009 to October 2011.

\section{Statistics and data handling}

Mean \pm standard deviation $(\mathrm{SD})$ median $\left(25^{\text {th }} ; 75^{\text {th }}\right.$ percentile) were used for continuous and percentages for categorical variables when analyzing as well as presenting data. Analysis was done stratified by age, using cut-off 60 months. Chi square, Fisher's exact test and student $t$-test were used to test for differences in proportion or mean between groups. Simple and multiple logistic regressions were employed to identify predictors of oedema, and odds ratio (OR) with $95 \%$ confidence interval $(\mathrm{CI})$ was reported. All the variables except "reported illness" were used in regression; the variable was omitted because of possible overlap in its information with "co-infection". Data was double entered using EpiData version 3 (EpiData Association, Odense, Denmark). Stata/IC 11.2 (StataCorp, Texas) was used for data analysis and WHO Anthro Plus v 1.0.3 (WHO, Geneva, Switzerland) to calculate Z-score 
using WHO growth standards. P-value $<0.05$ was considered significant.

\section{Results}

During the study period, a total of 527 SAM children (0.5 to 14 years of age) were admitted to the paediatric ward. From these, 176 (33.4\%) were excluded, mainly (96.7\%) due to critical illness. No differences were found between excluded and studied children when comparing their mean age (1.6 months, $95 \% \mathrm{CI},-4.2,7.4)$, and the proportions of females $(38.6 \% \mathrm{v} .43 .3 \%, \mathrm{p}=0.30)$, presence of oedema $(66.1 \%$ v. $61.1 \%, \mathrm{p}=0.26)$ and proportion of children under the age of five years $(75.6 \%$ v. $74.4 \%$, $\mathrm{p}=0.76$ )

In total, 351 children were included in the study. The median age was 36 months (interquartile range 24 to 60 ), and $261(74.4 \%)$ were under the age of five years. The proportion of females was lower among the younger children compared to older $(40.2 \%$ v. $52.2 \%, \mathrm{p}=0.05)$ (Table 1$)$.

Among the young children, 151 (57.8\%) had their mothers as attendants in the hospital (Table 1). In both age groups most children came from farming families, $187(71.6 \%)$ in the younger and $76(83.5 \%)$ in the older age group. There was no difference between the two age groups in parental schooling, household's access to toilet facility and safe water (Table 1). More children in the older group were admitted during the pre-harvest (June-Nov) season compared to the post-harvest period (Dec-May). However, there was no apparent seasonal variation for the young age group. The seasonal difference in admission between the two age groups was not significant.

The mean Z-scores of weight-for-age (WAZ), heightfor-age (HAZ) and BMI-for-age (BMIZ) for young children were -3.7 (95\% CI: -4.0, -3.5), -3.4 (95\% CI: -3.5,-3.1) and -2.4 (95\% CI: $-2.6,-2.2)$, respectively (Table 2). The means of these indices of the younger children, as shown in Table 2, were not different from that of the older children. The proportion of infection was significantly higher among the younger children $(33 \%$ v. $8.9 \%, \mathrm{p}<0.001)$ (Table 2). Pneumonia was the leading infection in both groups, with $23.0 \%$ and $4.4 \%$ affected, respectively.

Oedema was present in 214 (61.1\%) children (Table 2). Among these children 102 (47.7\%), 59 (27.6\%) and 53 $(24.8 \%)$ had oedema of grade "+", “++", and “+++", respectively (data not shown in table). There was no difference in the proportion and grade of oedema between the two age groups $(p=0.87)$. In the younger group, the proportion of oedema almost doubled after infancy and peaked at three to five years of age (Figure 1). The proportion of oedema was about one third lower among 96-168 months old children compared to 60-95 months $(p=0.003)$. However, in both age groups the mean HAZ and admissions seasons were comparable between children with and without oedema (Table 3).

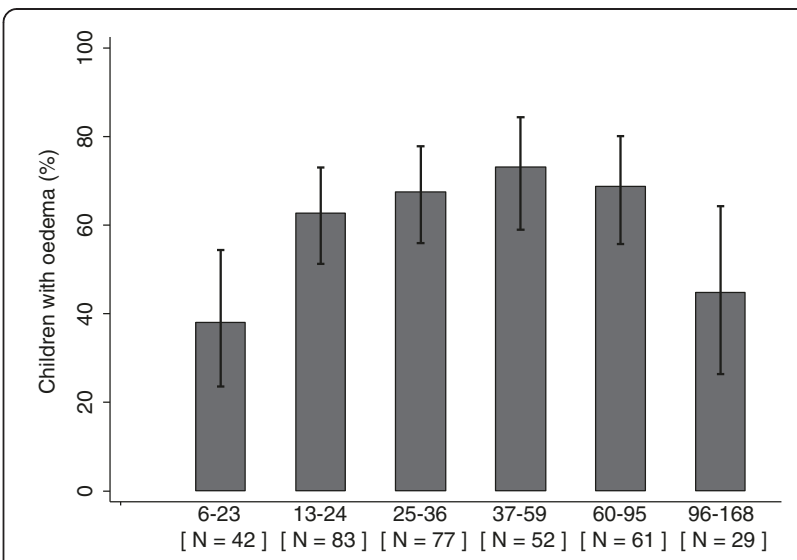

Figure 1 Percentage of severely malnourished children with oedema by age category in months. The error bars represent 95\% confidence intervals

In the younger group, oedematous children had significantly lower prevalence of infection compared to non-oedematous children $(25.2 \%$ v. $45.1 \%, \mathrm{p}=0.001)$. Nevertheless, in the older group the difference in prevalence of infections among oedematous and nonoedematous children was not significant, (5.5\% v. $14.3 \%$, $\mathrm{p}=0.17$ ). Finally, logistic regression was performed to determine predictors of oedema (Table 4).

The risk of oedema was lower for children 96-168 months of age as compared to $60-95$ months (OR $=0.34,95 \%$ CI: $0.13,0.88)$. Among the younger children, the odds of oedema was lower in children with TB (OR $=0.20$, 95\% CI: $0.06,0.70)$ or diarrhea, $(\mathrm{OR}=0.40,95 \% \mathrm{CI}$ : $0.21,0.73)$. These factors did not predict oedema in the older group, however.

\section{Discussion}

Most studies on SAM have focused on children under the age of five years. However, as shown in our study, a great proportion of children above the age of 5 were admitted with SAM. Overall, oedematous malnutrition affected around $60 \%$ of the children. Additionally, among children under the age of five years a positive relationship was found between age and oedema, whereas in the older children this relationship was reversed. Finally, the risk of oedema was found to be lower in children with infection.

The relationship between age and oedema is a significant finding from our study. There are hardly studies which investigated the age-oedema relationship in older children ( $>5$ years). Using logistic regression and as shown in Figure 1, the proportion of oedema doubled after infancy with peak at three-five years of age; the odds of oedema was also five times higher at three-five years of age as compared to infants. The odds and proportion of oedema, however, decreased with age after the age of three to five years. 
Table 3 Age, sex, height, weight, admission season and illness of severely malnourished children by presence of oedema and age group

\begin{tabular}{lll}
\hline $\begin{array}{ll}\text { Non-oedematous } \\
\mathrm{a}\end{array}$ & Oedematous $^{\mathrm{a}}$ & P-value \\
$\mathrm{n}=102$ & $\mathrm{n}=102$ \\
\hline
\end{tabular}

$$
<5 \mathrm{yr}
$$

Age category, mo

6-12
$13-24$
$25-36$
$37-59$

Height-for-age Z-score

Female sex

Admission season $^{b}$

Pre-harvest

Post-harvest

Co-infection $^{c}$

TB

Pneumonia

Diarrhea

Malaria

HIV status

Negative

Positive

Unknown

Reported illness ${ }^{d}$

Fever

Cough or difficult breathing

Diarrhea
Measles
$\geq 5 \mathrm{yr}$

Age category, mo

\begin{tabular}{cl} 
60-95 & $19(54.3)$ \\
96-168 & $16(45.7)$ \\
Height-for-age Z-score & $-3.3 \pm 1.5$ \\
Female sex & $22(63.0)$ \\
Admission season $^{\text {b }}$ & \\
Pre-harvest $^{\text {Post-harvest }}$ & $21(60.0)$ \\
Co-infection $^{c}$ & $14(40.0)$ \\
TB $^{\text {Pneumonia }}$ & $5(14.3)$ \\
Diarrhea & $2(5.7)$ \\
Malaria & $2(5.7)$ \\
& $2(5.7)$ \\
\hline V & $1(2.8)$
\end{tabular}

HIV status

Negative

$$
\begin{aligned}
& 31(30.4) \\
& 31(30.4) \\
& 25(24.5) \\
& 15(14.7) \\
& -3.5 \pm 1.8 \\
& 38(37.3)
\end{aligned}
$$

9 (8.8)

$n=35$

0.001

$17(10.7)$

52 (32.7)

52 (32.7)

38 (24.0)

$-3.2 \pm 1.6$

0.28

67 (42.1)

0.43

$73(45.9)$

86 (54.1)

40 (25.2)

0.001

$4(2.5)$

0.02

$27(17.0)$

0.01

25 (15.7)

0.002

$6(3.8)$

$106(66.7)$

$1(0.6)$

52 (32.7)

141 (88.7)

0.15

$106(66.7)$

0.06

76 (47.8)

0.001

$106(66.7) \quad 0.52$

0.20

$\mathrm{n}=55$

42 (76.4)

13 (23.6)

$-3.7 \pm 1.2$

0.51

25 (45.5)

21 (38.1)

$3(5.5)$

\begin{tabular}{|c|c|c|c|}
\hline Positive & $2(5.7)$ & $1(1.8)$ & \\
\hline Unknown & $12(34.3)$ & $14(25.5)$ & \\
\hline Reported illness ${ }^{d}$ & & & 0.72 \\
\hline Fever & $26(74.3)$ & $33(60.0)$ & 0.17 \\
\hline $\begin{array}{l}\text { Cough or difficult } \\
\text { breathing }\end{array}$ & $19(54.3)$ & $23(41.8)$ & 0.25 \\
\hline Diarrhea & $22(63.0)$ & 34 (61.8) & 0.92 \\
\hline Measles & $1(2.8)$ & $4(7.3)$ & 0.65 \\
\hline
\end{tabular}

Table 3 Age, sex, height, weight, admission season and illness of severely malnourished children by presence of oedema and age group (Continued)

Although the mechanism for this relationship is uncertain, there are some probable explanations. When children start to walk and explore their environment, their risk of acquiring infection or exposure to environmental contaminants is likely to increase [16]. Furthermore, the weaning process and gradual loss of maternally acquired immunity could contribute to increased infection. As a result, this infection or exposure to bacterial endotoxins may increase production of free radicals and oxidative stress $[17,18]$, which may lead to oedema. However, the interaction of immunity and infection and its result might be influenced by age. The requirement for a certain degree of immunocompetence for development of oedema in SAM children was suggested, based on a finding of lower $\mathrm{CD} 4+$ percentages in non-oedematous irrespective of their HIV status [19]. Furthermore, a study among Ugandan children showed that half the children hospitalized for severe malnutrition developed oedema after starting ART, although non-oedematous SAM is common in HIV-infected children [20]. So this might be a potential explanation for the higher risk of oedema with increasing age in the first five years. Its subsequent decline might be as a result of better immunity, and as a result lower risk of infection with increasing age.

Infection was found to be lower in oedematous SAM. It seems oedematous SAM is an acute disease usually presenting with shorter duration of illness. Its metabolic dysfunctions resemble that of acute conditions with high case fatality such as toxic shock syndrome and multi-organ failure [21]. Theoretically, this short duration might not be long enough for severe aberration in immunity to develop thus reducing the risk or severity of infection. In hospitals most deaths of SAM children, especially with oedema, are associated with infusion or transfusion [4]. Assessing and managing dehydration/shock in SAM children is also often difficult and incorrect [22]. 
Table 4 Factors associated with oedema among 351 children admitted with severe acute malnutrition with odds ratios (OR) and $95 \%$ confidence intervals $(\mathrm{CI})$

\begin{tabular}{|c|c|c|c|c|c|c|}
\hline & \multicolumn{2}{|c|}{ Simple logistic regression } & \multicolumn{4}{|c|}{ Multiple logistic regression } \\
\hline & \multirow[b]{2}{*}{ OR $(95 \% \mathrm{Cl})$} & \multirow[b]{2}{*}{ P-value } & \multicolumn{2}{|l|}{ Model I } & \multicolumn{2}{|l|}{ Model II } \\
\hline & & & OR $(95 \% \mathrm{Cl})$ & P-value & OR $(95 \% \mathrm{Cl})$ & P-value \\
\hline \multicolumn{7}{|l|}{$<5 \mathrm{yr}$} \\
\hline \multicolumn{7}{|l|}{ Age category, mo } \\
\hline $6-12$ & Reference & & Reference & & Reference & \\
\hline $13-24$ & $3.06(1.46 ; 6.41)$ & 0.003 & $3.11(1.48 ; 6.55)$ & 0.003 & $3.04(1.42 ; 6.53)$ & 0.04 \\
\hline $25-36$ & $3.80(1.77 ; 8.11)$ & 0.001 & $3.82(1.78 ; 8.18)$ & 0.001 & $3.67(1.67 ; 8.02)$ & 0.001 \\
\hline $37-59$ & $4.61(2.00 ; 10.71)$ & $<0.001$ & $4.74(2.04 ; 11.04)$ & $<0.001$ & $5.08(2.10 ; 12.35)$ & $<0.001$ \\
\hline Female sex & $1.25(0.75 ; 2.10)$ & 0.40 & $0.76(0.45 ; 1.30)$ & 0.35 & & \\
\hline Height-for-age Z-score & $1.08(0.93 ; 1.26)$ & 0.29 & $1.15(0.98 ; 1.35)$ & 0.09 & & \\
\hline \multicolumn{7}{|l|}{ Admission season ${ }^{a}$} \\
\hline Pre-harvest & Reference & & & & & \\
\hline Post-harvest & $1.43(0.87 ; 2.36)$ & 0.16 & $1.28(0.76 ; 2.14)$ & 0.35 & & \\
\hline \multicolumn{7}{|l|}{ Co-infection b } \\
\hline TB & $0.24(0.07 ; 0.78)$ & 0.02 & $0.16(0.04 ; 0.55)$ & 0.004 & $0.20(0.06 ; 0.70)$ & 0.01 \\
\hline Pneumonia & $0.44(0.25 ; 0.80)$ & 0.007 & $0.47(0.22 ; 0.76)$ & 0.02 & & \\
\hline Diarrhea & $0.41(0.22 ; 0.74)$ & 0.003 & $0.41(0.23 ; 0.81)$ & 0.004 & $0.40(0.21 ; 0.73)$ & 0.003 \\
\hline Malaria & $1.92(0.38 ; 9.71)$ & 0.43 & $2.0(0.37 ; 10.30)$ & 0.42 & & \\
\hline \multicolumn{7}{|l|}{ HIV status } \\
\hline Negative & Reference & & & & & \\
\hline Positive & $0.12(0.01 ; 1.08)$ & 0.06 & $0.14(0.02 ; 1.27)$ & 0.08 & & \\
\hline Unknown & $1.03(0.60 ; 1.79)$ & 0.91 & $1.15(0.66 ; 2.02)$ & 0.62 & & \\
\hline \multicolumn{7}{|l|}{ Reported illness ${ }^{c}$} \\
\hline Fever & $0.68(0.39 ; 1.20)$ & 0.18 & $0.73(0.41 ; 1.30)$ & 0.28 & & \\
\hline Diarrhea & $1.4(0.74 ; 2.08)$ & 0.42 & $1.25(0.73 ; 2.14)$ & 0.41 & & \\
\hline Cough & $0.44(0.26 ; 0.73)$ & 0.002 & $0.48(0.28 ; 0.82)$ & 0.007 & & \\
\hline Measles & $0.48(0.17 ; 1.32)$ & 0.15 & $0.61(0.21 ; 1.75)$ & 0.35 & & \\
\hline \multicolumn{7}{|l|}{$\geq 5 \mathrm{yr}$} \\
\hline \multicolumn{7}{|l|}{ Age category, mo } \\
\hline $60-95$ & Reference & & Reference & & & \\
\hline $96-168$ & $0.37(0.15 ; 0.91)$ & 0.03 & $0.39(0.16 ; 0.99)$ & 0.05 & $0.34(0.13 ; 0.88)$ & 0.03 \\
\hline Female sex & $0.47(0.20 ; 1.11)$ & 0.09 & & & & \\
\hline Height-for-age Z-score & $0.83(0.62 ; 1.12)$ & 0.23 & $0.83(0.60 ; 1.15)$ & 0.27 & & \\
\hline \multicolumn{7}{|l|}{ Admission season } \\
\hline Pre-harvest & Reference & & & & & \\
\hline Post-harvest & $0.93(0.39 ; 2.20)$ & 0.86 & $1.21(0.48 ; 3.05)$ & 0.71 & & \\
\hline \multicolumn{7}{|l|}{ Co-diagnoses $^{\mathrm{b}}$} \\
\hline TB & $0.25(0.02 ; 3.2)$ & 0.30 & $0.20(0.01 ; 2.20)$ & 0.18 & & \\
\hline Pneumonia & $0.31(0.04 ; 2.30)$ & 0.25 & $0.42(0.05 ; 3.34)$ & 0.42 & & \\
\hline Diarrhea & $0.15(0.01 ; 1.66)$ & 0.12 & $0.23(0.02 ; 2.18)$ & 0.20 & & \\
\hline
\end{tabular}


Table 4 Factors associated with oedema among 351 children admitted with severe acute malnutrition with odds ratios (OR) and $95 \%$ confidence intervals (CI) (Continued)

\begin{tabular}{|c|c|c|c|c|}
\hline \multicolumn{5}{|l|}{ HIV status } \\
\hline Negative & Reference & & & \\
\hline Positive & $0.28(0.02 ; 3.20)$ & 0.30 & $0.38(0.02 ; 4.66)$ & 0.45 \\
\hline Unknown & $0.64(0.25 ; 1.62)$ & 0.35 & $0.65(0.25 ; 1.71)$ & 0.38 \\
\hline \multicolumn{5}{|l|}{ Reported illness ${ }^{c}$} \\
\hline Fever & $0.52(0.20 ; 1.31)$ & 0.17 & $0.41(0.15 ; 1.12)$ & 0.08 \\
\hline Diarrhea & $0.96(0.40 ; 2.30)$ & 0.92 & $0.88(0.35 ; 2.18)$ & 0.78 \\
\hline Cough & $0.61(0.26 ; 1.42)$ & 0.25 & $0.60(0.24 ; 1.44)$ & 0.25 \\
\hline Measles & $2.67(0.30 ; 25.00)$ & 0.38 & $2.68(0.27 ; 27.0)$ & 0.40 \\
\hline
\end{tabular}

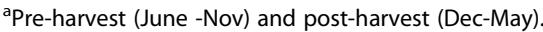

${ }^{\mathrm{b}}$ Major diagnoses during admission.

clllnesses within one month before admission as reported by caretaker.

Model I: adjusted for age and sex.

Model II: adjusted for age, sex, co-infection, admission season and height-for-age Z-score.

Younger children with TB were less likely to present with oedema. Macallan [23] showed that TB was associated with wasting, as a result of increased resting energy expenditure and anorexia. Wasting could be due to cytokine induced impairment of amino acids utilization for protein synthesis [24].

Experimental and prospective community studies are recommended to better understand the role of infectionimmunity interaction, and effect of age, in the pathogenesis of nutritional oedema [25]. Routine use of antibiotics during treatment of SAM has been questioned $[26,27]$. A recent trial showed that antibiotics improved recovery and reduced mortality [28]. However, similar evaluation has to be done in areas with low HIV prevalence. Last, in areas where undernutrition is common, older children should be routinely screened for SAM, at least in hospitals, and proper treatment instituted.

Generalization of our finding may be affected by certain limitations of the present study. First, selection bias is an inherent problem of hospital based studies. Hence, the general population of SAM children may not have been well represented. Second, the prevalence of infection might be underestimated due to the absence of detailed and systematic radiological and microbiological investigations to diagnose or exclude infection. Often, diagnosing infection in severely malnourished individuals is difficult and required detailed, and sometimes invasive microbiological investigations. Third, infants less than 6 months were excluded. Although not common, oedema has been documented in this group of children by previous studies [29]. Finally, there might be recall bias in estimating the child's age. Practically it is impossible to get recorded date of birth as almost all deliveries in rural Ethiopia take place at home [30].

\section{Conclusion}

The following two conclusions can be drawn from the present study. First, proportion of oedematous SAM peaked at three-five years of age. Second, the prevalence of infection was lower among children with oedematous SAM. Although the data are cross-sectional, the relationship suggest that oedema might result from the infectionimmunity interaction, which in turn could be influenced by age of the child.

\section{Competing interests}

The authors declare that they have no competing interests.

\section{Authors' contributions}

$\mathrm{TG}, \mathrm{PK}, \mathrm{KFM}, \mathrm{CM}$ and HF were involved in the conception and design of the study. TG, ALH and PK contributed to acquisition of data. TG, PK, KFM, CM and HF contributed to analyses and interpretation of the data. TG was responsible for writing up of the paper while all co-authors reviewed the draft manuscript. All authors read and approved the final manuscript.

\section{Acknowledgements}

The authors are grateful to the participants and their care takers/families as well as the staffs at the Pediatric ward of Jimma University Specialized Hospital. The study received funding from Danish International Development Agency through grants 104.DAN.8-1207 and 09-097 LIFE.

\section{Author details}

'Department of Pediatrics and Child Health, Jimma University Specialized Hospital, Jimma, Ethiopia. ${ }^{2}$ Department of Nutrition, Exercise and Sports University of Copenhagen Frederiksberg Campus, Rolighedsvej 30,

Frederiksberg C DK-1958, Denmark.

Received: 4 June 2013 Accepted: 27 November 2013

Published: 6 December 2013

\section{References}

1. Morris SS, Cogill B, Uauy R: Effective international action against undernutrition: why has it proven so difficult and what can be done to accelerate progress? Lancet 2008, 371(9612):608-621.

2. Caulfield LE, De Onis M, Blössner M, Black RE: Undernutrition as an underlying cause of child deaths associated with diarrhea, pneumonia, malaria, and measles. Am J Clin Nutr 2004, 80(1):193-198. 
3. World Health Organization: WHO, UNICEF, and SCN informal consultation on community-based management of severe malnutrition in children, SCN Nutrition Policy Paper No. 21. Geneva: World Health Organization; 2006.

4. Bachou H, Tumwine JK, Mwadime RKN, Tylleskär T: Risk factors in hospital deaths in severely malnourished children in Kampala, Uganda. BMC Pediatr 2006, 6:7.

5. Management of Severe Malnutirtion: A Manual for Physicians and Other Senior Health Workers. Geneva: WHO; 1999.

6. Dewji GN: Kwashiorkor: A protein deficiency disease. Nurs Times 1969, 65(17):523-524.

7. Fechner A, Böhme C, Gromer S, Funk M, Schirmer R, Becker K: Antioxidant status and nitric oxide in the malnutrition syndrome kwashiorkor. Pediatr Res 2001, 49(2):237-243.

8. Forrester TE, Badaloo AV, Boyne MS, Osmond C, Thompson D, Green C, Taylor-Bryan C, Barnett A, Soares-Wynter S, Hanson MA, Beedle AS, Gluckman PD, Bhutta ZA: Prenatal factors contribute to the emergence of Kwashiorkor or Marasmus in severe undernutrition: Evidence for the predictive adaptation model. PLOS ONE 2012, 7(4):e35907.

9. Henry FJ, Briend A, Fauveau V, Huttly SA, Yunus M, Chakraborty J: Gender and age differentials in risk factors for childhood malnutrition in Bangladesh. Ann Epidemiol 1993, 3(4):382-386.

10. Ighogboja SI: Some factors contributing to protein-energy malnutrition in the middle belt of Nigeria. East Afr Med J 1992, 69(10):566-571.

11. Jeyaseelan $L$, Lakshman M: Risk factors for malnutrition in south Indian children. J Biosoc Sci 1997, 29(1):93-100

12. Medhin G, Hanlon C, Dewey M, Alem A, Tesfaye F, Worku B, Tomlinson M, Prince $M$ : Prevalence and predictors of undernutrition among infants aged six and twelve months in Butajira. Ethiopia: The P-MaMiE Birth Cohort. BMC Public Health 2010, 10:27

13. Sharghi A, Kamran A, Faridan M: Evaluating risk factors for protein-energy malnutrition in children under the age of six years: A case-control study from Iran. Int J Gen Med 2011, 4:607-611.

14. Ethiopia Federal Ministry of Health: Protocol for the Management of Severe Acute Malnutrition, Ministry of Health-Federal Democratic Republic of Ethiopia. Ethiopia: Michael Golden and Yvonne Grellety; 2007.

15. Ethiopia Federal Ministry of Health: TBL and TB/HIV Prevention and control program manual, Ministry of Health- Federal Democratic Republic of Ethiopia. Ethiopia: Ethiopia Federal Ministry of Health; 2008.

16. Yatsunenko T, Rey FE, Manary MJ, Trehan I, Dominguez-Bello MG, Contreras M, Magris M, Hidalgo G, Baldassano RN, Anokhin AP, Heath AC, Warner B, Reeder J, Kuczynski J, Caporaso JG, Lozupone CA, Lauber C, Clemente JC, Knights D, Knight R, Gordon J: Human gut microbiome viewed across age and geography. Nature 2012, 486:222-227. Available from: http://www nature.com/doifinder/10.1038/nature11053.

17. Golden MH: Evolution of nutritional management of acute malnutrition. Indian Pediatr 2010, 47(8):667-678.

18. Manary MJ, Leeuwenburgh C, Heinecke JW: Increased oxidative stress in kwashiorkor. J Pediatr 2000, 137(3):421-424.

19. Bachou H, Tylleskär $T$, Downing $R$, Tumwine JK: Severe malnutrition with and without HIV-1 infection in hospitalised children in Kampala, Uganda: Differences in clinical features, haematological findings and CD4+ cell counts. Nutr J 2006, 5:27.

20. Prendergast $A$, Bwakura-Dangarembizi MF, Cook AD, Bakeera-Kitaka S, Natukunda E, Nahirya Ntege P, Nathoo K, Karungi C, Lutaakome J, Kekitiinwa A, Gibb DM: Hospitalization for severe malnutrition among HIV-infected children starting antiretroviral therapy. AIDS 2011, 25(7):951-956.

21. Mh G: Oedematous malnutrition. Br Med Bull 1998, 54:433-444

22. Maitland K: Symposium 5: Joint BAPEN and Nutrition Society Symposium on "Feeding size 0: The science of starvation" Severe malnutrition: Therapeutic challenges and treatment of hypovolaemic shock. Proc Nutr Soc 2009, 68(03):274

23. Macallan DC: Malnutrition in tuberculosis. Diagn Microbiol Infect Dis 1999, 34(2):153-157

24. Macallan DC, McNurlan MA, Kurpad AV, De Souza G, Shetty PS, Calder AG, Griffin GE: Whole body protein metabolism in human pulmonary tuberculosis and undernutrition: Evidence for anabolic block in tuberculosis. Clin Sci 1998, 94(3):321-331.

25. Smith MI, Yatsunenko T, Manary MJ, Trehan I, Mkakosya R, Cheng J, Kau AL, Rich SS, Concannon P, Mychaleckyj JC, Liu J, Houpt E, Li JV, Holmes E, Nicholson J, Knights D, Ursell LK, Knight R, Gordon Jl: Gut microbiomes of
Malawian twin pairs discordant for kwashiorkor. Science 2013, 339(6119):548-554

26. Lazzerini M, Tickell D: Antibiotics in severely malnourished children: Systematic review of efficacy, safety and pharmacokinetics. Bull World Health Organ 2011, 89(8):594-607.

27. Trehan I, Amthor RE, Maleta K, Manary MJ: Evaluation of the routine use of amoxicillin as part of the home-based treatment of severe acute malnutrition. Trop Med Int Health 2010, 15(9):1022-1028.

28. Trehan I, Goldbach HS, LaGrone LN, Meuli GJ, Wang RJ, Maleta KM, Manary $\mathrm{MJ}$ : Antibiotics as part of the management of severe acute malnutrition. N Engl J Med 2013, 368(5):425-435.

29. Begum A, Sharma JD, Azad AK, Mahmud NU, Ahmad M: Prevalence of oedematous malnutrition in early infancy. J Chittagong Med Coll Teach Assoc 2010, 21(1):50-55. Available from: http://www.banglajol.info/index. php/JCMCTA/article/view/7679.

30. Central Statistical Agency [Ethiopia] and ICF International: Ethiopia Demographic and Health Survey 2011. Addis Ababa, Ethiopia and Calverton, Maryland, USA: Central Statistical Agency and ICF International; 2012.

\section{doi:10.1186/1471-2431-13-204}

Cite this article as: Girma et al:: Predictors of oedema among children hospitalized with severe acute malnutrition in Jimma University Hospital, Ethiopia: a cross sectional study. BMC Pediatrics 2013 13:204

\section{Submit your next manuscript to BioMed Central and take full advantage of:}

- Convenient online submission

- Thorough peer review

- No space constraints or color figure charges

- Immediate publication on acceptance

- Inclusion in PubMed, CAS, Scopus and Google Scholar

- Research which is freely available for redistribution

Submit your manuscript at www.biomedcentral.com/submit
C BioMed Central 